\title{
Acompanhamento Terapêutico e a Relação Mãe-Bebê
}

Therapeutic Follow-up and the Mother-Baby Relationship

Acompañamiento Terapéutico y la Relación Madre-Bebé

\section{Daiane Engel, Mercês Sant'Anna Ghazzi \& Heloisa Cardoso da Silva}

Universidade Luterana do Brasil

http://dx.doi.org/10.1590/1982-370001022013

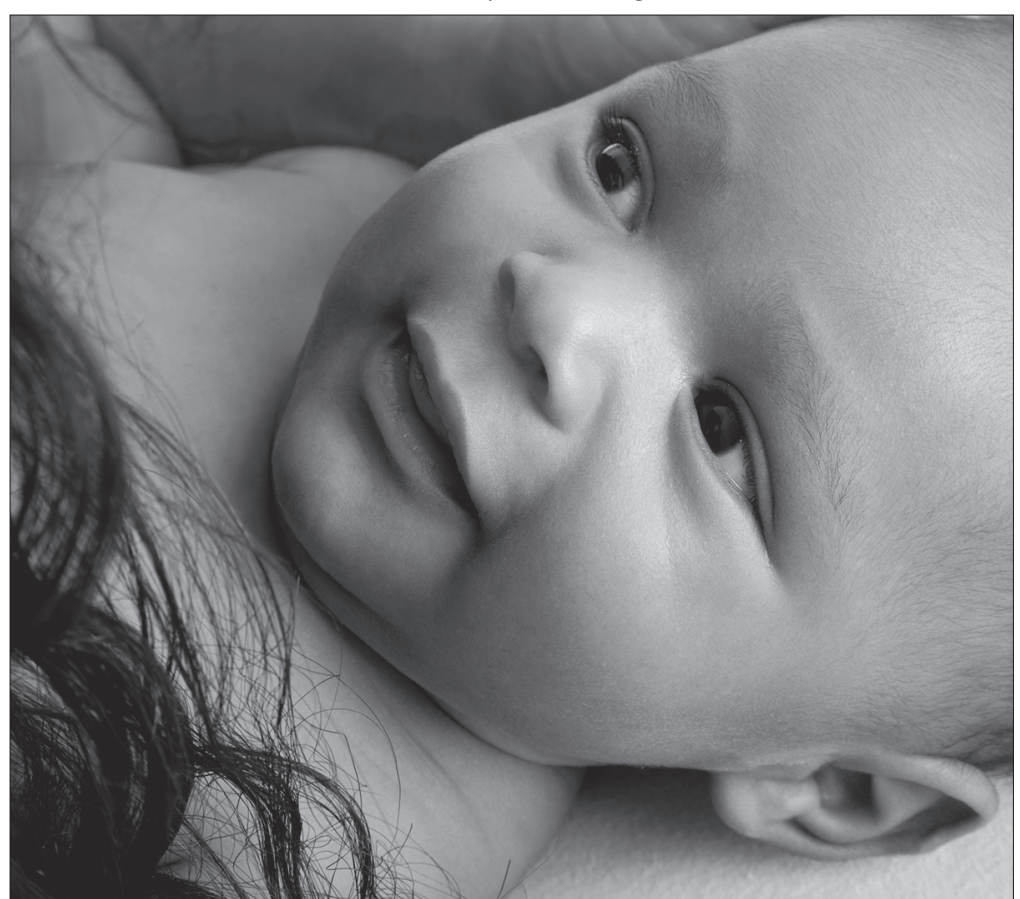


Resumo: O presente estudo busca refletir sobre a clínica do Acompanhamento Terapêutico (AT), indagando sobre a pertinência dessa intervenção junto a famílias de bebês que apresentem risco em sua estruturação psíquica. Para tal, realizou-se uma investigação teórica sobre o AT e sobre a clínica com bebês, os quais serviram de base para a análise dos fragmentos de um caso de AT, realizado com um bebê e sua mãe, junto ao Pró-bebê, o qual é um projeto de extensão que acompanha o desenvolvimento de crianças de zero a três anos em um posto de saúde de Torres/RS. A partir desses relatos, discutiu-se essa forma de intervenção, buscando comprovar a sua eficácia no atendimento a famílias com bebês que apresentem risco para seu desenvolvimento ou estruturação psíquica.

Palavras-chave: Acompanhamento terapêutico. Psicanálise. Relações mãe-criança. Saúde pública.

Abstract: This paper seeks to reflect on the Therapeutic Follow-up (TFU) clinic, questioning the pertinence of this intervention in families with babies presenting risk in their psychic structuring. To that end, a theoretical investigation was carried out on TFU, undertaken with one baby and the mother, which acted as basis for analysis of fragments from one TFU case, which is an extension Project that follows up the development of children from zero to three yrs old in a health unit of Torres/RS. This form of intervention was discussed, from those reports, seeking to evidence its efficacy in caring for families with babies presenting risk in their psychic development or structuring.

Keywords: Therapeutic Accompaniment. Psychoanalysis. Mother-child-relations. Public Health.

Resumen: El presente estudio busca reflexionar sobre la clínica del Acompañamiento Terapéutico (AT), indagando sobre la pertinencia de esa intervención junto a familias de bebés que presenten riesgo en su estructuración psíquica. Para tal, se realizó una investigación teórica sobre el AT y sobre la clínica con bebés, los cuales sirvieron de base para el análisis de los fragmentos de un caso de AT, realizado con un bebé y su madre, junto al Pro-bebé, el cual es un proyecto de extensión que acompaña el desarrollo de niños de cero a tres años en un puesto de salud de Torres/RS. A partir de esos relatos, se discutió esa forma de intervención, buscando comprobar su eficacia en el atendimiento a familias con bebés que presenten riesgo para su desarrollo o estructuración psíquica.

Palabras-clave: Acompañamiento terapéutico. Psicoanálisis. Relaciones madre-niño. Salud pública. 
O presente artigo busca refletir sobre a pertinência do Acompanhamento Terapêutico (AT) como dispositivo de intervenção junto a bebês em situação de risco psíquico por meio do relato de uma prática de AT domiciliar realizada junto a um bebê (do quinto ao décimo primeiro mês de sua vida) e sua família. Este trabalho faz parte das ações desenvolvidas pelo projeto de extensão Próbebê, o qual é vinculado à Universidade Luterana do Brasil - ULBRA - Torres/RS.

O Pró-bebê iniciou-se em 2001, em parceria com a prefeitura municipal, visando à identificação precoce de transtornos de desenvolvimento ou risco psíquico por meio da intervenção direta junto às famílias e seus bebês de zero a três anos. As práticas fundamentaram-se teoricamente na teoria psicanalítica e na psicogenética de Piaget, e para a realização dos trabalhos, foram utilizados, como instrumento de acompanhamento do desenvolvimento, as fichas de avaliação infantil do Ministério da Saúde (Brasil, 2002) e os Indicadores de Risco de Desenvolvimento Infantil (IRDI) (Jerusalinsky et al., 2008).

Os atendimentos às famílias e seus bebês foram realizados mensalmente pela professora coordenadora do projeto, alunos e psicólogos egressos da Universidade. Também foram realizadas capacitações junto às equipes de Estratégia de Saúde da Família, para que os agentes comunitários de saúde atuassem encaminhando ao atendimento os bebês, bem como realizando o acompanhamento das crianças que apresentem algum risco para o seu desenvolvimento. A partir disso, pôde-se perceber que, em alguns casos em que a criança apresentava risco em sua estruturação psíquica, a intervenção feita no posto e com a agente de saúde não era suficiente, o que levou a pensar em novas estratégias de ação. Entre elas, estavam as visitas domiciliares à criança e sua família e o AT no trabalho com mães e bebês que apresen- tassem maior dificuldade de comparecer ao posto e maior necessidade de sustentação das funções parentais.

\section{O Acompanhamento Terapêutico como Prática Clínica}

O Acompanhamento Terapêutico (AT) é uma intervenção clínica relativamente recente e são ainda pouco conhecidos os benefícios de sua indicação. O seu surgimento está intimamente ligado aos movimentos de desinstitucionalização da loucura na Inglaterra, Estados Unidos e Itália. Sua prática surgiu a partir dos anos 60, junto às comunidades terapêuticas na Argentina e/ou Brasil (Palombini, 2007).

Segundo Coelho (2007), o AT foi pensado como mais um recurso ao manejo clínico do sofrimento psíquico nas instituições psiquiátricas, surgindo como uma necessidade clínica em relação aos pacientes com quem as abordagens terapêuticas clássicas fracassavam. De acordo com os movimentos de não confinamento de pacientes, alguns profissionais passaram a exercer novas funções e a serem chamados de auxiliares psiquiátricos. Em seguida, passaram a ser chamados de amigo qualificado. Na década de 70, esse trabalho era realizado tanto nas comunidades terapêuticas quanto fora delas, junto aos consultórios de psiquiatria. No início dos anos 80, a partir de um movimento dos próprios acompanhantes, o nome amigo qualificado foi substituído pelo de Acompanhante Terapêutico (At) ${ }^{1}$. De acordo com a Equipe do Hospital-Dia A CASA (1991), esse termo não deveria ser mais definido pela continência oferecida (amizade), mas sim, por uma ação, uma ação junto à outra pessoa: o acompanhar.

O início da estruturação da prática do AT se deu na década de 80 , mediante a enfatização do trabalho terapêutico pessoal do pro- 
fissional e da supervisão dos atendimentos por meio de uma sistematização necessária à formação teórica e prática do AT. Neto (1995) apresenta o AT como um campo de intervenção que não deve ser determinado como uma técnica, podendo, assim, a partir de diferentes concepções teóricas e ideológicas, ser visto por diversos olhares.

Atualmente, a prática do AT tem se legitimado na abertura de novas possibilidades de ação profissional na área da saúde, caracterizada pela ação interdisciplinar e pelo modelo de atenção psicossocial. Isso se relaciona ao que traz Carrozzo (1991), que diz que a intervenção do AT é realizada por especialistas em pessoalidade, por especialistas em poder estar nas relações, estabelecer transferências e suportá-las, sempre se referenciando a um grupo, equipe e instituição implicadas nessa rede relacional.

Pode-se definir o AT como uma clínica sem muros que se realiza no espaço aberto do urbano, acompanhando cotidianos de vida de forma a favorecer o estabelecimento de laços entre o sujeito acompanhado e o território por ele habitado (Palombini, 2007).

Segundo Ribeiro (2002), o AT é uma prática paralela ao atendimento de pessoas que estejam em sofrimento psíquico; esse acompanhamento, no dia a dia do paciente, oferece diferentes recursos de atuação, bem como cria condições para transformar essa situação de crise podendo descobrir as potencialidades desses casos, pois faz uma intervenção na dinâmica familiar e social. Configura-se, então, como um ponto de referência estável à família que se encontra desorganizada e sem saber lidar com dificuldades relativas à estruturação psíquica, pois, como pontuam Guerra e Milagres (2005), ao agir no real da cena, emprestando seu corpo e sua fala à intervenção, o AT também promove a cena e a desenvolve.

\section{Como se poderia pensar o Acompanhamento Terapêutico na clínica com bebês?}

A prática clínica com um bebê deve ser situada de um modo diferenciado do AT com uma criança maior, com um adolescente ou com o adulto. No atendimento com um bebê, é necessário incluir seus pais ou seus cuidadores, levando em conta o modo como eles se implicam na vida dessa criança e a forma com que se fazem presentes os padecimentos e as manifestações patológicas de um ser que ainda não fala.

O desenvolvimento infantil fundamenta-se na estruturação psíquica e nas aquisições instrumentais, ou seja, para que um bebê se constitua é necessário que ele estabeleça um laço com o Outro, que na primeira infância é sustentado pela função materna. Quando acontece alguma dificuldade no estabelecimento desse laço, seja ela causada pelo exercício da paternidade ou maternidade com o filho ou pelo comunicado de um diagnóstico de patologia ou síndrome, o bebê pode produzir um sintoma. É justamente nesse ponto, quando um bebê produz um sintoma nesse circuito de realizações de ideais sociais e parentais, que ele é trazido a tratamento (Jerusalinsky, 2002a). Sendo assim, o trabalho na clínica com bebês deve-se fazer junto ao Outro parental que o sustenta, posto que é a partir da relação que se arma entre o bebê e sua família que poderá ser possível intervir. Dessa forma, pensar na clínica do AT no trabalho com bebês necessita considerar que, no mínimo, serão dois os acompanhados, já que um bebê não se sustenta sem a presença de sua mãe, mas, além dela, muitos outros podem estar presentes na cena, como os pais, tios e avós.

A partir da atuação no projeto, a implementação do AT configurou-se como um desafio por dois motivos: primeiro, porque é uma 
prática bastante recente, sendo escasso o material bibliográfico relacionado à infância; segundo, o atendimento nesse caso tem como objetivo auxiliar os pais e o bebê para que ele possa estruturar-se psiquicamente, $\mathrm{o}$ que diferencia essa prática de AT das demais, que estão geralmente voltadas para a melhor adaptação de sujeitos com patologias psíquicas severas já instaladas.

Sabe-se que a prática que se dedica ao trabalho com bebês com dificuldades em seu desenvolvimento é definida como Estimulação Precoce (EP). De acordo com Jerusalinsky e Coriat (1997), a clínica em EP tem como objetivo apoiar a criança no desenvolvimento de seus aspectos instrumentais, enquadrando-se na interdependência de outras disciplinas teórico-técnicas. Para esses autores, a estimulação dirige-se à criança em seu todo e não somente a uma parte dela, envolvendo assim todo o seu desenvolvimento cognitivo e comportamental. O trabaIho com a criança deve partir da ação possível e não daquela que está afetada por uma incapacidade específica.

A prática que foi desenvolvida nesse caso não pode ser caracterizada como EP, pois não há intervenção específica sobre os aspectos instrumentais, no entanto, leva em conta que, ao trabalharmos junto a um bebê e sua mãe, fazse necessário levar em conta esses aspectos, sustentando o possível para o bebê junto à sua família. Dessa forma, foi proposta a intervenção por meio do AT, buscando estabelecer uma sustentação às mães que apresentassem maior fragilidade psíquica, como nos casos de depressão materna ou dificuldades relativas ao laço social, possibilitando, assim, que a mãe pudesse desempenhar a função materna. Isso se justifica pelo fato de que os primeiros momentos de vida de uma criança supõem o estabelecimento de um laço, o qual está sustentado pelo laço social presente na comunidade em que a família está inserida, mas que, de forma alguma, está dado inconscientemente de forma prévia, constituindo-se a partir da chegada do bebê. Sendo assim, no risco da não constituição do laço parental, um acompanhamento pode se fazer necessário no sentido de promover e sustentar sua instalação.

Para que um bebê se constitua, é necessária uma relação com o mundo externo, que no primeiro momento é representado pela relação que ele estabelece com a mãe. É a partir das inscrições simbólicas proporcionadas pelo agente materno que ele se constituirá, sendo a função materna que abrirá, ou não, lugar para a inscrição paterna, pela qual o bebê poderá responder a partir de um funcionamento desejante.

De acordo com Campanário (2008), quando o estabelecimento dessa relação com o agente maternante apresenta sinais de dificuldades que restrinjam a singularização subjetiva do bebê, este se encontra em risco psíquico. No entanto, por se tratar de bebês, sabe-se que, se a estruturação está em seu início, os sintomas de uma patologia, quando detectados precocemente, se trabalhados, podem ser transformados. Para que isso aconteça, é necessário que o terapeuta estabeleça um vínculo transferencial com a criança e seu meio, a fim de sustentar as aquisições do bebê junto aos pais, o que lhes permite não privilegiar o sintoma, mas sim seu filho. Dessa forma, acredita-se que o AT, amparado no atendimento psicanalítico pode vir a se configurar em uma importante forma de intervenção junto a determinadas famílias em que o bebê apresente algum tipo de risco.

Segundo Guerra e Milagres (2005), em casos graves de risco para a estruturação psíquica, o que deve ser buscado não é o real somático de uma função, mas as condições simbólicas do sujeito para enfrentar o real do gozo do Outro, ou seja, é preciso conhecer o mundo do sujeito e seguir suas estratégias, a fim de desenvolver uma política para inter- 
venção. Seguindo essa perspectiva, Zenoni (2000) comenta que a problemática clínica é inseparável do contexto social do sujeito, apontando a necessidade de articulação da dimensão social do sujeito com a dimensão clínica do social. O autor afirma que uma pragmática cotidiana, se tomada a partir do ponto de vista da clínica, permite um arranjo mais viável da situação futura do sujeito, o que, no caso de bebês, leva a pensar na importância da constituição e sustentação dos laços que permitirão as relações com o Outro (Guerra \& Milagres, 2005).

Se o que se encontra no referencial teórico é que o AT opera a partir do imaginário, vêse aqui que, na clínica com bebês, o At opera a partir do real da cena, emprestando seu corpo e suas palavras à intervenção. Pode-se dizer que o At trabalha com seu ser e que se coloca como um espelho vivo para o acompanhado (Guerra \& Milagres, 2005).

Assim, pode-se afirmar que, na clínica com bebês, o At atuaria como um espelho vivo para a mãe, para sua relação com o bebê, suportando o lugar do Outro, que, para ela, faz-se impossível ocupar. A partir disso, o At vai atuar com o bebê, a mãe e o pai, possibilitando um amparo que sustente as aquisições da criança no ambiente familiar. Pode-se pensar que ele constituiria um trabalho em parceria com o clínico em EP ou com o psicanalista que atende a família, porém em um espaço diferente do consultório, possibilitando a circulação da mãe e do bebê em situações sociais em que a clínica clássica não teria alcance.

\section{O caso em questão}

O caso discutido neste trabalho vem sendo acompanhado a partir da modalidade de ação do projeto Pró-Bebê. As agentes de saúde, capacitadas para tal, identificaram um para acompanhamento. Para iniciar os atendimentos, os responsáveis pela criança assinaram um termo de consentimento livre e esclarecido autorizando a equipe do projeto a utilizar os dados obtidos para fins de estudos, pesquisas e publicações, com a garantia de sigilo de seus dados pessoais. Após isso, no posto, realizou-se a avaliação a partir do instrumento utilizado para avaliação e da escuta psicanalítica.

João ${ }^{2}$ foi trazido ao posto por seus pais para ser atendido pelo Pró-bebê. No primeiro atendimento, ele dormia e a mãe não se referenciava muito ao bebê. No segundo encontro, aos quatro meses, o pai e a mãe vieram para o acompanhamento bastante angustiados em relação a João e a seu desenvolvimento. O menino não olhava para os pais ou outras pessoas nem trocava olhares com a mãe. Também não havia a presença do manhês, como forma particular de fala, dirigida pelos pais às crianças muito pequenas, nas quais há alterações lexicais, prosódicas e sintáticas, com frases curtas, simples e em tom de voz agudo e alto (Catão, 2009). Além disso, outra importante característica do manhês não estava presente na interação da mãe com João, pois não havia, na fala materna, uma alternância em que ela assumisse a sua posição e a do bebê, falando por ele em interpretação a seus atos (Ferreira, 2001). O pai, por outro lado, utilizava-se mais do manhês e, após muito conversar com João, conseguiu convocar seu olhar, chamando-o por um apelido, que lhe pareceu causar interesse e mudança de atitude. Nessa cena, pôde-se observar a ausência dos indicadores de risco do desenvolvimento infantil (IRDI) (Jerusalinsky et al., 2008), o que indica, nesse momento, fragilidade na sua estruturação psíquica e no exercício das funções paterna e materna. Além disso, não apresentou o desenvolvimento motor esperado para sua faixa etária, tendo em vista que João não passava da posição lateral para a linha média. 
Após esses atendimentos, realizados junto ao posto de saúde com João e seus pais, e com as informações da equipe do posto de saúde - diziam que essa mãe parecia precisar que a visitassem - optou-se pela instalação da modalidade de AT semanal, realizado por uma estagiária de Psicologia. A família passou a ser acompanhada semanalmente por ela no domicílio, recebendo atendimento psicanalítico quinzenal no posto. Simultaneamente, a família continuou sendo visitada pela agente da saúde e pela enfermeira, tendo acompanhamento de pediatra fora do posto.

Na primeira visita de AT, João dormia na chegada da At, sendo, então, acordado pela mãe. Foi solicitado à mãe que chamasse o menino, o que, de início, foi feito timidamente. Por um longo período, o olhar de João estava perdido, porém a mãe continuou a convocá-lo. Ela parecia desanimar e foi necessário que a At também o chamasse e dissesse para a mãe que não desistisse. Após muito insistir, a mãe conseguiu captar o interesse de João, que a olhou, mas por pouco tempo. A mãe contou que a pediatra e a equipe do posto haviam encaminhado João para um neurologista, dizendo estar muito nervosa: "Eu não sei o que vai acontecer, eu sei que o João está muito atrasado, tenho medo [de] que ele tenha algum problema grave, pois ele já está com seis meses e ainda não senta e nem segura a cabeça". A At manteve uma posição de tranquilizar a mãe, falando o quanto era importante ela estimular o menino para que ele respondesse ao seu chamado e ao seu olhar, bem como da importância de investimento nas ações dele.

A partir dos atendimentos realizados, percebeu-se que o pai conseguia capturar o olhar do menino com mais facilidade que a mãe, falando com ele em manhês e chamando-o por um apelido, o que denotava a suposição de sujeito em João, permitindo-lhe interagir com o pai. A mãe deu-se conta disso e, em um dos atendimentos no posto, disse: " $\mathrm{Eu}$ comecei a imitar o pai dele para que ele me olh [olhass].". Nesse momento, notou-se uma mudança de posição subjetiva da mãe, tendo seus efeitos no transcorrer do caso.

No terceiro atendimento da At, o menino já atendeu mais rapidamente ao chamado da mãe, porém, também se percebeu que, para que isso ocorresse, a voz precisava estar acompanhada do toque materno. A At ressaltou a importância de a mãe oferecer um objeto para a criança, juntamente com sua voz e seu toque. Viu-se, assim, uma mãe mais tranquila, o que levou a pensar o quanto, nessas situações, a intervenção parecia consistir em sustentar à mãe a possibilidade de exercer a função materna, auxiliando-a a acreditar nas aquisições e supor um sujeito em seu filho. Isso foi confirmado pela sequência dos atendimentos, pois, um mês e meio após seu início, o menino atendia mais ao chamado materno, fixando mais o olhar nos objetos e interagindo mais com o outro, sinais de um avanço em seu desenvolvimento.

Na quarta visita, a mãe contou que João se divertia no banho, sendo, então, combinado um momento de banho para a sessão seguinte. Nesse dia, a mãe, ao colocá-lo na banheira, disse: "ele adora tomar banho, fica assim esparramado, se sente à vontade". Nesse momento, o menino batia o pé na água e a mãe logo dizia: "Viu como ele gosta até brincar na água". A At, então, direcionou seu olhar ao menino e falou: "Você gosta de tomar banho, João?". A mãe olhou para ele, sorriu e falou em manhês: "Né, filho, conta pra tia que você adora tomar banho, gosta de ficar na água". Nesse momento, já se pôde observar uma mudança de posição da mãe, que dava significado a cada movimento de João, dizendo o que ele fazia e queria, simbolizando e significando como desejantes as produções do menino. 
Conforme os atendimentos foram seguindo e o laço transferencial se estabelecendo, começaram a surgir, nos encontros, dados sobre a história familiar: o pai, ex-usuário de drogas, preocupava-se que isso pudesse ter afetado o desenvolvimento do filho. Algum tempo depois, surgiu também o relato sobre a condição de filho adotivo do pai.

Viu-se, a cada atendimento, o quanto o acompanhamento residencial permitiu à mãe a construção de uma narrativa sobre sua história, a do marido e a do filho; ao mesmo tempo, tornou-se um importante elemento de sustentação dessa mãe e dessa criança. Assim, pode-se dizer que, nos nove meses em que João esteve em atendimento, o caso teve uma evolução importante. O menino já respondia instantaneamente ao chamado da mãe, assim como a terceiros, principalmente aqueles de seu convívio. Fazia balbucios e a mãe dava significado a suas ações. Notou-se que a mãe inseriu a At no discurso que dirigia ao bebê. A relação que se armou na casa denotava a possibilidade de que a cena encontrasse uma significação discursiva, que era dada a ver pela mãe à At, que compartiIhava da mesma cena.

O menino também estava apresentando episódios de estranhamento a locais e a outras pessoas diferentes de sua mãe, sendo acalmado por ela. Esse comportamento de João parecia anunciar a angústia do oitavo mês, indicativo de uma importante diferenciação entre a mãe e os demais, demarcando a constituição da mãe como figura da qual a criança depende e junto a qual se sente segura (Spitz,1960).

\section{Discussão}

Na produção teórica encontrada, percebeu-se que o AT está voltado para a reabilitação social de pacientes psicóticos. No entanto, o caso aqui proposto para discus- são não trata de uma intervenção em uma psicose já constituída e nem de uma reabilitação ao meio social, trata-se, pelo contrário, de uma estrutura a ser construída a partir da relação desse bebê com seus pais e seu meio social. Portanto, pode-se pensar que, independentemente da estrutura em que essa criança venha a se firmar, estar-seá atuando na sua habilitação ao meio, ou seja, da humanização.

Além disso, o AT, no caso de João, não trabalha direta e unicamente com ele, pois ainda é um bebê e, na clínica com bebês, o trabalho se dá juntamente com a mãe e o pai. Segundo Jerusalinsky (2002a), a clínica com bebês "opera pela precoce intervenção de traços que, a partir dos cuidados parentais e das produções do bebê, indicam problemas no marco da constituição no bebê" ( $p$. 36). Desse modo, após verificar os primeiros indicativos de que a constituição do bebê não vai bem, é permitido e aconselhável iniciar a intervenção, pois, é nesse tempo da infância, nos primórdios da constituição psíquica, que estão sendo estabelecidas as primeiras inscrições de seu funcionamento psíquico, logo, há um tempo em que ainda é possível prevenir a instalação de psicopatologias precoces. No caso de João, aos quatro meses, quando foi identificado risco em sua estruturação psíquica e em seu desenvolvimento, começou-se a trabalhar com ele e sua família.

Quando o menino chegou a atendimento, poder-se-ia dizer que tinha pais muito frágeis, que não conseguiam se situar de forma estruturante para ele. Como referido anteriormente, João foi trazido pelos pais, que se mostravam muito angustiados e preocupados com o fato dele não lhes direcionar o olhar. O trabalho com eles se iniciou buscando apontar a importância de que falassem com o menino e que pudessem convocá-lo. Segundo Jerusalinsky (2002a), a 
clínica com bebês fica situada justamente no avesso dos best-sellers de aconselhamentos a pais e "técnicas estimulantes de aptidões do bebê" (p. 23), porque ocorre a partir do ponto em que se encontra um fracasso na realização dos ideais sobre maternidade, paternidade e primeira infância. Sendo assim, o trabalho clínico, diante de tal fracasso, deve operar pela escuta, sustentação e intervenção dos interrogantes pelos quais cada pai e mãe ficam singularmente implicados com o seu filho, em lugar de partir do aconselhamento anônimo.

No caso de João, o trabalho não se deu apenas a partir da escuta dos pais, já que houve, além da intervenção psicanalítica, a de uma At. Assim, supõe-se que a intervenção com um suporte mais ativo na residência familiar, proporcionando a escuta desses pais, angustiados com o sintoma do filho, sem interpretá-los, nem dizer o que se considera certo ou errado em suas atitudes, possibilitou a atuação junto à criança e a identificação dos interrogantes desses pais com esse filho.

O AT, para Ribeiro (2002), situa-se como uma prática paralela ao atendimento de pessoas que estejam em sofrimento psíquico, que oferece diferentes recursos de atuação, bem como cria condições para transformar essa situação de crise, podendo descobrir as potencialidades desses casos, pois faz uma intervenção na dinâmica familiar e social. O At é, então, um ponto de referência estável a essa família que se encontra desorganizada e sem saber lidar com o problema de seu filho, junto ao laço social em que ela se encontra inserida.

Pôde-se perceber a importância do trabalho com esse caso, pois a família de João era uma família extremamente reservada e um tanto quanto isolada. Com a inserção da At na residência, a mãe foi confiando cada vez mais nela, podendo narrar eventos impor- tantes da história familiar e cenas cotidianas do desenvolvimento do bebê.

Segundo Lins, Oliveira e Coutinho (2009), o At atua em grupo, formando uma equipe que compartilha um mesmo plano de tratamento. Assim, a transferência, como suposição de saber a um outro a quem se endereça uma fala a respeito do próprio sofrimento (Hermann, 2008), no caso de João, foi sustentada pelo trabalho em equipe do posto de saúde, realizado com o bebê e sua mãe. Jerusalinsky (2002b) colabora dizendo que, em tal contexto, o AT marca a sua especificidade ao dar sustentação no cotidiano às intervenções que se operam desde o tratamento clínico. Nos atendimentos realizados pela At, a mãe sempre lhe pedia um parecer sobre o desenvolvimento do menino, assim como conselhos a respeito de seus comportamentos. Em um dos atendimentos, a mãe chamou muitas vezes o filho, que não lhe respondeu. Após muito insistir, ela conseguiu capturar-Ihe olhar. Em seguida, ele direcionou o seu olhar a um brinquedo e a mãe, angustiada, falou à At: "Não sei o que acontece. Por que ele não me olha e não responde as vezes que [o] chamo? $\mathrm{O}$ que você acha que posso fazer para chamar a atenção dele?" Ao tentar conter a angústia da mãe, a At pediu para que ela continuasse a chamá-lo, usando um chocalho. A mãe pegou o brinquedo, sacudiu e o chamou; ele, em seguida, olhou-a, estimulando-a a chamá-lo com cada vez mais interesse. Assim, aqui não se trata de uma interpretação, como se daria em um atendimento psicanalítico junto à mãe, mas sim, de uma intervenção clínica que mescla orientação e sustentação da tentativa da mãe de se relacionar com seu bebê.

Outro aspecto que se deve destacar referente à transferência é a angústia. Na clínica com bebês, ela se manifesta em todos aqueles implicados em seu atendimento. Se, nos 
bebês, ela se expressa preferencialmente por meio de seu corpo e diz respeito à sua interação com o outro cuidador, nos pais, manifesta-se por meio da própria enunciação da queixa - uma preocupação com seu bebê. Já no analista, a angústia refere-se aos aspectos arcaicos em jogo na transferência e também à preocupação, própria dessa clínica, relativa ao tempo cronológico, tempo evolutivo que conta particularmente na primeira infância, na medida em que a maturação, o crescimento e o desenvolvimento são cruciais para que se opere a intersecção com o tempo lógico das operações psíquicas fundamentais (Bernardino, 2008).

No caso de João, a angústia transferencial também se manifestou na At, angústia que teve seu lugar na supervisão, que lhe permitia reconhecer os benefícios de suas intervenções, assim como seus momentos de angústia. É no setting terapêutico, nesse caso, na casa do bebê ou na rua, que essas angústias se encontram e que, na trama da escuta, vão poder se transformar em palavras em busca de significações. É por meio da escuta que se situa desde que lugar subjetivo o acompanhado fala, para então ser possível manejar a transferência.

A partir da prática do acompanhamento e da transferência estabelecida, pode-se pensar também na questão da sustentação simbólica ofertada à mãe que, por consequência, era transmitida ao bebê. Assim, a At pôde sustentar os significantes na transferência de modo a não interpretá-los, ofertando um espaço de construção simbólica e imaginária sobre as produções da criança junto a seu meio social. Várias foram as visitas realizadas em que se encontrou uma mãe desanimada, desorientada, que não sabia o que fazer com seu bebê. Nesses momentos, foi necessário reanimar a mãe para que ela continuasse a investir no menino. Assim, foi possível dizer-lhe sobre os progressos que conseguiu em relação ao desenvolvimento de João e o quanto mudou enquanto mãe, o que pareceu deixá-la mais interessada. Em um atendimento no posto, realizado pela psicanalista e pela At, a mãe, sentada no chão, brincando com João, disse-lhe, com um tom de voz característico do manhês, a seguinte frase: "É, o João nasceu primeiro e a mamãe depois".

Nesse ponto, percebeu-se que a presença da At se fez de extrema importância para a mãe, pois a amparou em suas questões referentes ao desempenho da função materna. Como se pôde ver, primeiramente houve um acoIhimento à mãe que lhe deu suporte e ofertou continência, permitindo-lhe fazer o mesmo com seu bebê. É justamente a atuação da At no domicílio dos pais que possibilitou essa intervenção, pois, ao se inserir na realidade da família e em seu cotidiano, pôde falar desde um lugar que inclui o laço social que sustenta simbolicamente os pais, porém, não se identificando a este e sim, dando suporte para que esse laço se fortaleça. Além disso, ao acompanhar a mãe e seu bebê, pôde atuar como testemunha da competência materna nos cuidados com o menino em sua casa. Nos atendimentos, foi notória a importância dada pela mãe e o efeito dessa ação quando a At mostrou um progresso de João.

Em uma situação em que a mãe contou que o menino estava batendo palmas, o que vinha tentando ensinar-lhe há vários meses, ela disse: "Joãozinho, conta pra tia o que você está fazendo, mostra pra ela que você já sabe bater palminhas". A At dirigiu-se ao menino e disse-lhe: "Que legal, João, você já está batendo palminhas". Então, o menino sorriu e bateu palmas. A mãe, frente a isso, ficou radiante. Nessa cena, viu-se o que Boukobza observou em sua experiência de atendimento a mães em dificuldades: "tínhamos o sentimento de que era preciso assistir, no real da sua vivência cotidiana, o 
casal mãe-bebê, dar um continente para que a palavra pudesse ter seu efeito" (Bernardino, 2008, p. 91).

Sendo assim, a sustentação simbólica que a At faz na relação mãe-bebê pode ser definida como o que Winnicott (1975) chama de holding - o acolhimento que uma mãe deve proporcionar ao seu bebê no sentido de continência, tanto física quanto psíquica. No caso de João, a At atuava fazendo holding para a mãe, ou seja, dando sustentação para que esta exercesse a função materna, o que Boukobza nomeou de holding do holding. Em outras palavras, o acompanhamento terapêutico com bebês trata-se de uma ação indireta com estes e de uma ação direta com os pais, principalmente com a mãe (Bernardino, 2008).

Como se vê, o trabalho no AT não se dá em um setting. A cena do trabalho se monta a partir dos locais conhecidos pelo paciente e das relações que estabelece. Assim, contribui para que, junto com sua família, possa estabelecer outras relações com o meio social. Toma-se aqui, como exemplo, um atendimento em que a At e a mãe, sentadas no tapete da casa, brincavam com João. Ao ver que uma vizinha chegou a casa, a mãe convidou-a para entrar e disse à criança: "Olha quem chegou, meu filho, é a vó Ana." Elas, então, contaram à At que eram muito amigas e que Ana considerava João como um neto. Ana foi convidada para sentar no tapete e, nesse momento, João sorriu, balbuciando e balançando os braços. Percebeu-se, nesse exemplo, o quanto esse trabalho pôde contribuir para reforçar a interação de João com outras pessoas e não apenas com o outro materno, compartilhando com a mãe a apresentação do social ao bebê e o estabelecimento do laço social.

Segundo Herzog (2004), o sujeito se constitui na e pela alteridade simbólica, sendo im- prescindível, assim, concebê-lo em sua inserção no campo social. É nesse campo que a relação simbólica com o Outro se exerce, sendo assim, o laço social se refere a tudo que sustenta o sujeito em um sentido simbólico e social. Assim, tanto o laço com a vizinha como os laços comunitários dos pais foram sustentados pelo acompanhamento já que estavam fragilizados em função das dificuldades do menino e da família - o que auxiliou os pais a sustentá-los para o menino.

Finalizando, pode-se pensar que no caso de João, a At constituiu um suporte para o seu desenvolvimento, fazendo intervenções no cotidiano que jamais poderiam ter sido feitas em uma sala do posto de saúde. Além disso, percebeu-se, por meio das cenas citadas, que a fala da At entrelaçou a mãe, João e o pai, dando-lhes sustentação no estabelecimento de suas funções. Enfim, pode-se dizer que a At atuou desde o acolhimento do sofrimento em jogo até a sustentação das funções que fraquejavam indo ao encontro das palavras e dos discursos que organizam as memórias e os lugares responsáveis pela estruturação de um pequeno sujeito junto à sua família.

\section{Considerações Finais}

O percurso traçado neste artigo visava a discutir a pertinência do AT como forma de intervenção junto a famílias de bebês, enfocando, em especial, o trabalho em equipe junto às equipes de saúde. A partir do caso tomado como exemplo, pôde-se perceber a importância desse trabalho para a evolução da criança e da família em atendimento.

Com o decorrer dos atendimentos, foi possível verificar a pertinência dessa estratégia, pois, por meio deles, observou-se, na criança, o início da estruturação psíquica mediante o laço com o Outro, encarnado pela mãe. 
Também foi possível evidenciar a importância da articulação do trabalho de AT com as visitas domiciliares e o trabalho de rede, realizados pela equipe do posto de saúde.

A partir das intervenções da At, ocorridas na comunidade, na casa da família, viu-se o quanto os pais de João foram, aos poucos, reposicionando-se. Ou seja, o trabalho de AT ofertou-lhes uma sustentação que lhes permitiu ocupar suas funções frente ao universo simbólico/imaginário no qual estavam inseridos. É a partir do AT que se pôde notar a construção de um laço que sustentou não só a mãe como também o bebê, ou seja, um laço social, que supõe tanto a sustentação da função materna, como da função paterna junto à mãe e seu bebê. Pode-se dizer que, ao acompanhá-los, atuou-se como testemunha da competência desses pais em cuidarem de seu bebê em um espaço que supõe o meio cultural no qual encontravam-se, meio que, se lhes provoca angústia por demandar produções de seu bebê, também pode lhes ofertar reconhecimento a cada nova aquisição da criança.

Dessa forma, pode-se pensar o AT, na clínica com bebês, como um atendimento que funciona exatamente por estar fora do posto de saúde, fora do espaço clínico clássico ou, brincando com a expressão de Guerra e Milagres (2005), que situam o AT como um atendimento "fora da casinha", na clínica com bebês, ele pode ser pensado como uma intervenção que se dá "fora da salinha". 


\section{Daiane Engel}

Graduada em Psicologia pela Universidade Luterana do Brasil, Torres/RS. Brasil. E-mail: daianengel@hotmail.com

\section{Mercês Sant'Anna Ghazzi}

Mestre em Psicologia pela Pontifícia Universidade Católica do Rio Grande do Sul, Porto Alegre - RS. Brasil. Docente da Universidade Luterana do Brasil, Torres/RS. Brasil e Professora do curso de Psicologia da Faculdade São Francisco de Assis - Rio Grande do Sul/RS

E-mail:nmm.ez@terra.com.br

\section{Heloisa Cardoso da Silva}

Mestre em Psicologia Clínica pela Universidade do Vale do Rio dos Sinos, São Leopoldo/RS. Brasil.

E-mail: helo-cardoso@hotmail.com

Endereço para envio de correspondência:

Rua Estrada Geral, nº 1822. CEP: 95575-000. Três Forquilhas/RS. Brasil.

Recebido 23/01/2013, Aprovado 07/10/2014 
Bernardino, L. M. F. (2008). A angústia na clínica psicanalítica com bebês e seus pais. In Associação Psicanalítica de Porto Alegre. Revista da Associação Psicanalítica de Porto Alegre. Da Infância à Adolescência: os tempos do sujeito (pp. 21-29). 35.

Brasil, Ministério da Saúde, Secretaria de Políticas de Saúde. (2002). Saúde da criança: acompanhamento do crescimento e desenvolvimento infantil. Brasília, DF. (Série cadernos de atenção básica; $n$ 11. Série a. Normas e manuais técnicos, n. 173).

Campanário, I. S. (2008). Espelho, espelho meu: a psicanálise e o tratamento precoce do autismo e outras patologias graves. Salvador, BA: Ágalma.

Carrozzo, N. L. M. (1991). Campo da criação, campo terapêutico. In Equipe de acompanhantes terapêuticos do hospital-dia "A Casa". (Orgs.) A rua como espaço clínico: acompanhante terapêutico (pp. 31-40). São Paulo: Escuta.

Catão, I. (2009). O bebê nasce pela boca: voz, sujeito e clínica do autismo. São Paulo: Instituto Langage.

Coelho, C. F. M. (2007). Convivendo com Miguel e Mônica: uma proposta de acompanhamento terapêutico de crianças autistas. Dissertação de Mestrado, Universidade de Brasília, Brasília, DF.

Equipe de acompanhantes terapêuticos do hospitaldia "A Casa" (Orgs.). (1991). A rua como espaço clínico. Acompanhamento Terapêutico. São Paulo: Escuta.

Ferreira, S. S. (2001). Por que falar ao bebê se ele não compreende? In M. do C., Camarotti. Atendimento ao bebê: uma abordagem interdisciplinar (pp. 97-116). São Paulo. Casa do Psicólogo.

Guerra, A. M. C., \& Milagres, A. F. (2005). Com quantos paus se faz um acompanhamento terapêutico? Contribuições da psicanálise a essa clínica em construção. Estilos da Clínica, 10(19), 60-83. Recuperado de http://pepsic.bvsalud.org/scielo.php?pid=S141571282005000200004\&script=sci_arttext

Hermann, M. C. (2008). Acompanhamento terapêutico e psicose: um articulador no real, simbólico e imaginário. Tese de Doutorado, Instituto de Psicologia, Universidade de São Paulo, São Paulo.

Herzog, R. (2004). O Laço social na contemporaneidade. Revista Latinoamericana de Psicopato- logia Fundamental, 2(3), 40-55. Recuperado de: http://www.fundamentalpsychopathology.org

Jerusalinsky, A., \& Coriat, L. (1997). Definição de estimulação precoce. In Centro Lydia Coriat. (Orgs.). Escritos da Criança. (3a ed, pp. 74-77). Porto Alegre.

Jerusalinsky, A., Kupfer, M. C., Bernardino, L. F., Wanderley, D., Rocha, P., Molina, S. et al (2008). Valor preditivo de indicadores clínicos de risco psíquico para o desenvolvimento infantil: um estudo a partir da teoria psicanalítica. Recuperado do Centro Lydia Coriat: www.lydiacoriat.com.br.

Jerusalinsky, J. (2002a). Enquanto o futuro não vem: a psicanálise na clínica interdisciplinar com bebês. Salvador, BA: Ágalma.

Jerusalinsky, J. (2002b). O Acompanhamento terapêutico e a construção de um protagonismo. Pulsional. Revista de Psicanálise. 15 (162), 32-41.

Lins, C. E., Oliveira, V. M., \& Coutinho, M. F. (2009). Clínica ampliada em saúde mental: cuidar e suposição de saber no acompanhamento terapêutico. Ciência e Saúde Coletiva, 14 (1), 105-215. doi: 10.1590/S1413-81232009000100026

Neto, R. R. (1995). O acompanhante terapêutico: trajetória histórica de uma prática em saúde mental no Rio de Janeiro. Dissertação de Mestrado, Departamento de Psicologia, Pontifícia Universidade Católica do Rio de Janeiro, Rio de Janeiro.

Palombini, A. de L. (2007). Vertigens de uma psicanálise a céu aberto: contribuições do acompanhamento terapêutico à clínica na reforma psiquiátrica. Tese de Doutorado, Instituto de Medicina Social, Universidade Estadual do Rio de Janeiro, Rio de Janeiro.

Ribeiro, T. C. (2002). Acompanhar é uma barra: considerações teóricas e clínicas sobre o acompanhamento psicoterapêutico. Psicologia: Ciência e Profissão, 22(2), 78-87. doi: 10.1590/S141498932002000200010

Spitz, R. (1960). A. Desenvolvimento emocional do recém-nascido. Rio de Janeiro: Livraria Pioneira Editora.

Winnicott, D. W. (1975). O brincar e a realidade. Rio de Janeiro: Imago.

Zenoni, A. (2000). Psicanálise e instituição: a segunda clínica de Lacan. (pp. 9-93). Belo Horizonte: Abrecampos. 